\title{
LA ARTICULACIÓN ECONÓMICA PREHISPÁNICA DEL PERÚ SUR ANDINO
}

\author{
THE PREHISPANIC ECONOMIC ARTICULATIONS \\ IN THE ANDES OF SOUTHERN PERU
}

\author{
Carlos F. Garaycochea*
}

\begin{abstract}
Se formula una visión integrada de las conexiones políticas, culturales, religiosas y principalmente económicas que tuvieron los Wari y Tiwanaku y sobre las que después se estructura parte del estado Inca. Se usa un enfoque multidisciplinario que permitió identificar y describir en los territorios andinos del sur del Perú algunas de las principales rutas que establecieron estas civilizaciones. Se concluye que hubo hasta tres espacios de encuentro y tensión entre Wari y Tiwanaku y se plantea la hipótesis de un patrón de conexiones basadas en intercambios económicos que, articuladas muchas veces a lo religioso, permanecieron inclusive después de los Inca, contribuyendo a su organización económica.
\end{abstract}

Palabras claves: Rutas Wari, rutas Tiwanaku, economía prehispánica, intercambios económicos, rutas sagradas, conectividad histórica.

It is proposed an integrated vision of political, cultural, religious and economic connections that Wari and Tiwanaku had and over which the Inca state was structured. A multidisciplinary approach was used to identify and describe in the Andean areas of Southern Peru some of the main routes established by these civilizations. It was concluded that there were three encounter spaces (and tension) between Wari and Tiwanaku and it was set the hypothesis of a pattern of connections based on economic exchanges, many times linked to religious issues, which remained even after the Inca state, contributing to her economic organization.

Key words: Wari Routes, Tiwanacu Routes, prehispanic economy, economic exchanges, sacred routes, historical connectivity.

\section{Introducción}

Este ensayo de historia económica propone encontrar y discutir las conexiones, en particular económicas, que se formaron en los territorios Wari, Tiwanaku e Inca y entre ellos, durante el milenio anterior a la llegada de los españoles. El estudio se limita al territorio del actual sur andino del Perú, suroeste de Bolivia y norte de Chile, en el que convergen factores de orden geográfico, ambiental y de recursos económicos que incidieron en estas civilizaciones y sus interacciones en el periodo analizado ${ }^{1}$. El enfoque es etnohistórico en el sentido que se adoptó un método multidisciplinario y el criterio orientador en la interpretación ha sido encontrar elementos que contribuyan a la historia económica de estas sociedades (Regalado 2013, 26). La arqueología, de gran desarrollo en décadas recientes, proporciona evidencias de la presencia y actividades de las sociedades prehispánicas que ocuparon este espacio. La geografía y sus enfoques recientes de orden ambiental permiten comprender su realidad física y también encontrar en el territorio las posibles rutas resultado de sus conexiones. En la documentación colonial temprana se encontró elementos que trascienden el tiempo prehispánico y confirman algunas continuidades históricas que persisten.

La economía del estado Inca que encuentran los españoles fue percibida a partir de su experiencia directa y de explicaciones que los cronistas recogieron. Se asumió la idea que los Inca habían sido los creadores de su cultura y organización social y que antes de ellos solo hubo pueblos bárbaros, a pesar que conocieron lugares como Huari o Tiawanaku (Cieza 1988, 207-209, 234). El conocimiento actual ha aclarado esta percepción y se siguen encontrando elementos que permiten comprender que los Inca fueron el resultado de un largo proceso histórico del que adquirieron y adaptaron muchos aspectos en la formación de su sociedad.

Las evidencias arqueológicas Wari y Tiwanaku constituyen partes de un espacio articulado por relaciones políticas, culturales y económicas que

* Pontificia Universidad Católica del Perú. Lima, Perú. Correo electrónico: cgaraiko@ gmail.com 
pasaron a otros pueblos en un largo proceso histórico y dieron sustento a la formación del estado inca. El estudio de la economía prehispánica requiere conocer este tramado de conexiones. Un concepto a tener en cuenta es que la realidad andina está compuesta de una amplia y diversa gama de zonas ecológicas con complejos sistemas ambientales que condicionan la utilización de sus recursos económicos. Esto fue conocido por los pueblos andinos desde tiempos inmemoriales, lo que lleva a considerar que no hay un solo modelo económico que encaje en esta diversidad ${ }^{2}$.

Las dataciones que proporciona la arqueología siguen mejorando y con ello la lenta construcción de una historicidad de Wari y Tiwanaku. Esta información está principalmente en tipologías cerámicas, diseños arquitectónicos, descripciones de tejidos, herramientas y, lo que es más importante desde el punto de vista económico: materiales de fabricación y productos finales para diferentes usos. Las evidencias arqueológicas sugieren interacciones de diferente tipo y configuran redes de conexiones asociadas a procesos sociales que se dieron en su tiempo y que en muchos casos persistieron dejando importantes vestigios. De manera particular se considera que las relaciones ideológicas y económicas fueron más estables dentro de este conjunto contribuyendo a procesos posteriores.

Un concepto muy importante es la integración de lo religioso con lo económico y que se entiende mejor en los movimientos de personas y en el uso de los recursos. Las caravanas de peregrinos hacia santuarios lejanos de gran prestigio o hacia las huacas locales o en la misma cuenca (Curátola 2008: 16-20) implicaron movimientos económicos que se expresaron en una logística material de movilización, en una preparación y traslado de ofrendas, en la realización de festividades y en la circunstancia concurrente para la realización de intercambios económicos y otros arreglos sociales. A esto hay que añadir la utilización, algunas veces obligada, de recursos económicos, como tierras de cultivo o pastos, para fines religiosos.

Como lo hemos precisado en otro trabajo, los intercambios intra e interétnicos son esencialmente por reciprocidad, pero también tienen un contenido económico cuando se trata de transacciones entre dos o más partes o agentes que intercambian bienes o servicios a una determinada tasa (Garaycochea 2014: 208-211). Estas transacciones tienen que ver con la escasez de recursos económicos, su diversidad, su complementariedad, especialización, distancias y otros factores. Son intercambios que se revelan en fuentes arqueológicas con el examen del origen de objetos, sus diseños y contenido ideológico, sus técnicas de fabricación y que plantean la posibilidad de rutas.

La utilización del espacio físico que ocuparon estas sociedades estuvo condicionada por la morfología territorial y por la densidad variable de sus relaciones políticas, culturales y económicas desde su centro de irradiación. Este enfoque está sustentado en varios trabajos presentados en 1998 sobre las fronteras interior y exterior del estado Inca (Dillehay y Netherly 1998). Este enfoque también es aplicable a los casos Wari y Tiwanaku, en los que se encuentra un centro de control político y espacios periféricos en los que dicho control se va diluyendo aunque la influencia cultural y económica permanece. Estas conexiones se pueden clasificar en intangibles y tangibles. Son intangibles cuando se refieren a relaciones religiosas y culturales, y comprenden creencias, conocimientos, leyendas, costumbres, ritos, idioma y técnicas (Garaycochea 2013: 4). Las conexiones tangibles son relaciones de dependencia recíproca como los intercambios de bienes y movimientos de personas. Estas conexiones en la realidad territorial se concretan en rutas definidas en las que transitan personas como militares, artífices, trasportadores de bienes, sacerdotes y en determinados momentos funcionarios y migrantes ${ }^{3}$.

Las evidencias arqueológicas constituyen una base para identificar redes conectivas. Cada evidencia sugiere preguntas: ¿Cómo un diseño o material viajaron desde su lugar de origen para influenciar un proceso de fabricación situado a cientos de kilómetros de distancia? ¿Cómo una idea religiosa del dibujo de un ceramio llegó aquí? ¿Cómo una técnica de fabricar textiles o canales de regadío fue aprendida? ¿Cómo estos productos encontrados en adoratorios, viviendas o almacenes llegaron allí? Entonces, cada sitio arqueológico genera la idea de un movimiento de personas que han discurrido por determinadas rutas. Plantea una hipótesis de caravanas que fueron buscando en la geografía los caminos para concretar el objetivo que tuvieron: realizar una ofrenda, participar en una festividad, afianzar una alianza, obtener determinados productos, consolidar una expansión u otros. Es así como aparecen hechos económicos que llevan a la identificación de rutas por las que transitaron productos de consumo final e intermedio, como 
es el caso de los intercambios de mullu, bronce u obsidiana (Murra 2002:171, Lechtman y MacFarlane 2006, Burger 2006).

El ámbito territorial del sur del Perú en el periodo de análisis, desde el punto de vista del análisis geográfico, muestra rasgos importantes como una gran anchura latitudinal de los Andes, una densa cadena volcánica ${ }^{4}$, el lago Titicaca con su enorme cuenca altiplánica y la vecindad con espacios de la Amazonía y parte del desierto de Atacama, de severa influencia climática. Hacia el océano Pacífico este espacio tiene cuatro cuencas de gran volumen hídrico y con conocidos y casi inaccesibles cañones, de los ríos: a) Maran-Cotahuasi-Ocoña, b) Colca-Camaná, c) Chili-Vitor y d) Tambo. Más hacia el sur están las pequeñas cuencas de los ríos Osmore, Sama, Locumba, Caplina, y Lluta, que apenas llegan al mar. Hacia la Amazonía están las cuencas longitudinales de los ríos Pampas, Apurímac y Urubamba. Esta compleja morfología y la diversidad de sistemas ambientales ${ }^{5}$ que contiene fueron la base territorial sobre la que se desarrollaron las sociedades andinas y que establecieron una red de conexiones entre ellas. Es una historia de superación de ambientes difíciles, domesticación de plantas y animales, modificación del paisaje para obtener tierras cultivables, además de la adaptación y superación a cambios climáticos y eventos catastróficos (Thompson et al. $1986 \mathrm{y}$ Huertas 2009).

\section{Los espacios Wari y sus conexiones}

Wari fue una sociedad andina cuya naturaleza política sigue en discusión, que algunos la consideran un imperio, otros una confederación e inclusive solo como una corriente cultural globalizante (Jennings 2010a, Shady 1988, Schreiber 2014 y Jennings 2010b). Lo importante es que Wari revela el surgimiento intenso de conexiones de las que ha quedado evidencia en un amplio territorio de los Andes desde Cajamarca hasta Moquegua y de la costa a la Amazonía. La cultura Wari se irradió desde los valles centrales de Ayacucho en torno a las ciudades de Huari y Conchopata ${ }^{6}$. Su espacio de control administrativo se extendió a lugares como Jincamoqo, Pikillacta, Wiracochapampa, Wariwillca, Honcopampa, Huaro y quizá Huarmey. Tuvo alguna forma estatal que ejerció un control político y que posiblemente exigió también un tributo. Asimismo implicó la construcción de una red de caminos que la arqueología está descubriendo (Schreiber 1991) y que en parte se integraron al sistema vial Inca. En la Figura 1 que se adjunta se describen las principales conexiones Wari y Tiwanaku.

\section{Conexiones religiosas}

Es muy probable que las primeras rutas hayan sido hacia santuarios religiosos, como su propia pacarina, la laguna de Choclococha que además alimenta la cuenca del río Pampas, en donde la civilización Wari se inicia y se expande. Un segundo e importante destino religioso que conviene examinar es el nevado de Pariacaca, huaca sagrada anterior a los Inca y de gran prestigio en la sierra central. Existió una ruta transversal que pudieron usar los Wari desde Xauxa, en el río Mantaro y entrada hacia territorio de los "anti" o la Amazonía, que sube hacia el nevado Pariacaca y de allí baja hacia Pachacámac. Esta ruta transversal es mencionada en algunos relatos del documento de Huarochirí (Taylor 1987: 259). Una segunda alternativa hacia Pachacámac fue quizá desde la laguna de Choclococha hacia Huaytará, que es un paso natural, geográficamente muy conveniente para descender hacia los valles costeros o yungas y la ruta hacia el santuario de Pachacámac. Lo que sí ha quedado comprobado fehacientemente es que hubo una presencia Wari en Pachacámac como lo atestiguan las evidencias arqueológicas que dejaron como ofrendas en este santuario y que fueron analizadas por diversos estudiosos que señalaron el gran apogeo y prestigio que tuvo este santuario en el Horizonte Medio (Rostworowski 1992: 84-87).

También hubo una ruta, principalmente religiosa, en dirección a lo que después fue el Cuntisuyo inca. Esta ruta se inicia en los valles y altiplanicies del sur del espacio Wari, en la actual provincia de Lucanas, donde se ubica el sitio arqueológico de Sondondo y se encamina hacia la laguna de Parinacochas, que mira hacia el sur el nevado Sara-Sara y luego los nevados Solimana, Coropuna, Ampato, Mismi, Sabancaya, Chachani, Misti y Pichu-Pichu, que alimentan las cuencas de Cotahuasi-Ocoña, ColcaCamaná y Chili-Vitor, en Arequipa. Se trata de varias montañas casi alineadas hacia el sur este, todas ellas huacas o santuarios de prestigio que se han mencionado en documentos coloniales tempranos o en los que se ha encontrado restos de ofrendas o han sido materia de estudios (Ziólkowski 2009, Guamán Poma 1987: f272 y f277). Es una ruta que 


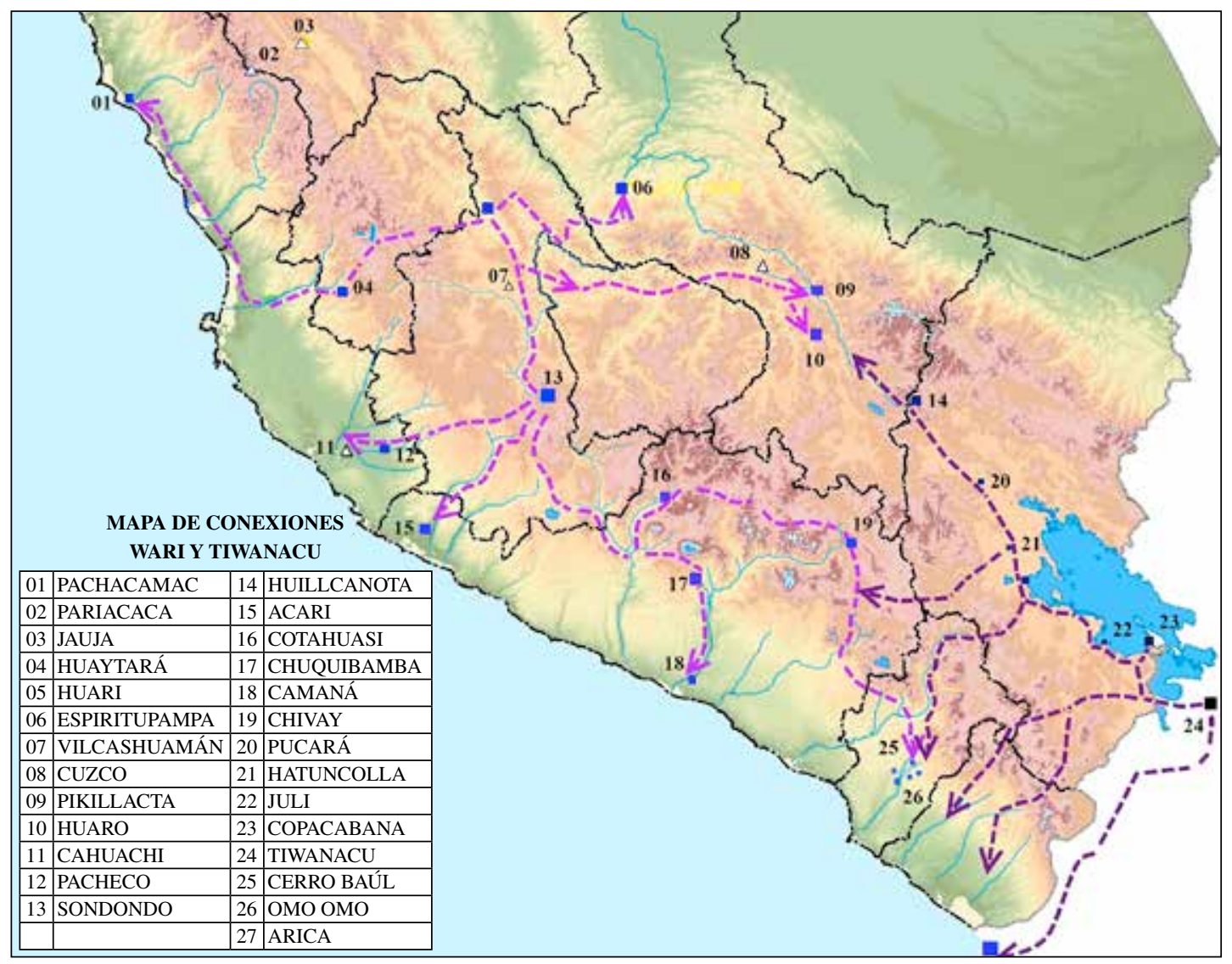

Figura 1. Mapa Conexiones Wari Tiwanaku.

finalmente termina en los valles del río Chili, en Arequipa, y se acerca a cerro Baúl en Moquegua.

La clave de esta ruta es el análisis geográfico de la cuenca del rio Marán, que al unirse con los ríos Cotahuasi y Chichas (o Arma) forman el río Ocoña. Se trata de una gran cuenca con tres grandes orígenes montañosos propicia para la interconexión fluida de poblaciones de norte y sur. En esta región estratégica se produjo la articulación ideológica y cultural entre los espacios Wari-Nazca y el que después los Inca denominarían Cuntisuyu y donde, en el Intermedio Tardío, estará la presencia dominante de los Collagua en las cuencas vecinas de los ríos Colca-Camaná y Chili-Vitor. Son rutas en las que hubo intercambios de objetos de prestigio como ceramios finos, textiles y adornos metálicos, además de los posibles movimientos de artífices (Jennings 2010b: 42). Al otro lado del Coropuna está Chuquibamba, donde se encontraron textiles de influencia Nazca-Wari (Frame 1999) y en los que se descubrió la vinculación entre los calendarios Wari e Inca (Zuidema 2011). Esta ruta posiblemente fue trajinada por los Inca. Garcilaso, al describir las andanzas del inca Mayta Cápac hacia el Contisuyu señala: ...de Parihuana Cocha ...pasó el despoblado de Coropuna... que los indios, con mucha consideración llaman Huaca ...entró en la provincia llamada Aruni; de allí pasó a otra que dicen Collahua, que llega hasta el valle de Arequepa,... (Garcilaso de la Vega 1959: 145). Es razonable asumir que los Inca al transitar por el Cuntisuyo tuvieron un destino que era la cuenca del río Chili, y de allí hacia el Collao o hacia Chile. En esta última cuenca la ruta continúa en el camino Inca usado hasta tiempos republicanos por lugares e hitos característicos como Paucarpata, Socabaya, Polobaya y Putina, entre otros, y de allí a las cuencas del Tambo y de Moquegua. Es importante recordar que la presencia Wari está comprobada en el valle Camaná-Siguas y cerca del valle del Chili-Vítor, donde hay varios sitios de filiación Wari en investigación como el 
de Corralones, cerca de Uchumayo. Es decir, que los Wari se desplazaron hacia Moquegua, sea por Acarí y Camaná como lo sugiere Jennings o por la ruta del Cuntisuyu hacia los valles de Arequipa y luego Omate en el río Tambo y de allí a cerro Baúl (Jennings 2014).

\section{Conexiones económicas}

Las conexiones económicas tienen que ver principalmente con la disponibilidad de recursos de tierra de cultivo y agua y, en segundo término, con la posibilidad de relacionarse con otras etnias que puedan ofrecer productos de intercambio que no se disponen. Hay que tener en cuenta que los valles de Ayacucho son pobres en calidad de tierras y su morfología compleja con varias cuencas profundas que dificultan su articulación. En este sentido, los Wari, utilizando sus vinculaciones culturales y religiosas, pudieron percibir el potencial económico de Nazca y Cuzco.

La presencia de los Nazca en Ayacucho es anterior a los Wari ${ }^{7}$. Sus testimonios en cerámica $\mathrm{y}$ textiles sugieren que su prestigio fue significativo al llegar al primer milenio d.C y llegó a Huarpa y luego a Huari. La civilización Nazca se desarrolló en la cuenca del río Grande y tuvo influencia en las cuencas vecinas de los ríos de Pisco, Ica y Acarí, así como en sus cabeceras en Castrovirreina, cerca de la laguna de Choclococha, y en las serranías de Ayacucho (Orefici 1998, Poma 1987: f85 y f354; Schreiber 2000). La presencia Wari en la cuenca del río Grande, en los sitios llamados Pacheco y Huaca de Loro, ocurrió cuando Nazca estaba en su fase declinante (Conlee y Schreiber 2006: 98 e Isbell 2010: 210). La motivación principal fue la abundancia de recursos agrícolas de la cuenca y los intercambios de productos textiles y alimentarios, que se explican por su complementariedad ecológica. Pero también un posible intercambio de conocimientos en arquitectura y construcción de canales, viviendas, depósitos y centros rituales, imágenes, materiales y diseños para cerámica. Pero la contribución Nazca más importante fue el manejo de sistemas hídricos, canales y puquios, que incidió en una agricultura muy productiva y diversificada, capaz tanto de sostener a su población como de generar excedentes e intercambios con otras cuencas. Los Wari adaptaron mucho de esta tecnología productiva en su propio espacio central y posiblemente la llevaron a otras cuencas en las que ejercieron una influencia cultural (Schneider y Lancho 2006: 8, 11).

La segunda ruta de expansión económica fue hacia los fértiles valles del río Urubamba. Fue una ruta difícil, ya que primero tuvieron que imponerse a los pueblos del lado occidental del río Apurímac, lugar agreste y con muchos pequeños valles pero de poca importancia económica. Es decir, atravesar lo que después sería el espacio de los Chanka, para luego cruzar el río Apurímac y establecerse en Huaro y Pikillacta, al sur de Cuzco. Los análisis arqueológicos han confirmado el control administrativo, la influencia cultural y los intercambios económicos que ejercieron los Wari, lo que implicó una ruta para el tránsito de ejércitos, administradores y también de agentes religiosos y económicos que posiblemente es anterior a los Wari (Glowacki y McEwan 2001: 39, Glowacki 2014: 195).

Los Wari pudieron haber establecido rutas que tenían un fin económico más exclusivo, como es el caso de una segunda conexión hacia la cuenca del río Urubamba que se descubrió en el 2010, en el valle de Espíritupampa, en la provincia que los Inca llamaron Vilcabamba, donde se encontró una tumba señorial Wari (Fonseca 2011). Esto hizo evidente una ruta que posiblemente se inició en Huari, remontó la cordillera oriental para travesar el río Apurímac, sobrepasó la cordillera de Vilcabamba ${ }^{8}$ y bajó hacia el valle de Espíritupampa, ya en la Amazonía, que se conecta con el río Urubamba, territorio que los Inca después llamarían del reino de lo "anti". Al analizar esta ruta sugerimos que tuvo la función principal de intercambio económico con las poblaciones de la Amazonía para productos como plumas, madera chonta, oro, sal, coca y otros (Garaycochea 2013) ${ }^{9}$.

\section{Conexiones administrativas}

$\mathrm{Al}$ analizar las conexiones administrativas se toca inevitablemente el tema de la naturaleza de la organización política de los Wari que aun está en debate. Surge el argumento que las conexiones económicas que implican alguna forma de extraer y apropiarse de un excedente y transportarlo hacia el espacio Wari central o, conservarlo y utilizarlo en espacios con control ya consolidado, plantean un manejo administrativo. Igualmente la influencia cultural y económica de desplazamientos humanos plantea igual necesidad. También se añade la evidencia de una ideología militar que ha sido 
destacada por algunos investigadores (Ochatoma 2000 y Tung 2012) y que es complementaria tanto a una modalidad de expansión militarista como a procesos de consolidación de la presencia Wari en algunos espacios conquistados. En suma, supone la existencia de conexiones de orden administrativo, que complementan otras funciones.

Hacia el norte, más allá de Pachacámac, las investigaciones arqueológicas han mostrado la presencia Wari en lugares relativamente alejados como Cajamarca y Huarmey ${ }^{10}$ y se ha generado el debate sobre si la presencia Wari fue solamente cultural y económica y no administrativa. Asimismo, en el caso de Huaro (Glowacki 2014), la interpretación de las evidencias arqueológicas que se tiene indican que hubo un control administrativo de la zona que posiblemente se extendió hacia Pikillacta cuando este lugar comenzó a construirse. Esto lleva a que es razonable asumir que entre el centro político de Wari y esta zona en el Cuzco hubo una conexión continua que significó un flujo importante de personas que cumplían diferentes funciones, entre ellas de control administrativo.

Una consideración especial merece la conexión que hubo con cerro Baúl, en el río Osmore de Moquegua. Como lo señalan los arqueólogos, este lugar ubicado sobre la cresta de un cerro que domina la parte central del valle contiene varias estructuras administrativas y religiosas (Williams et al. 2001, 75). Su ubicación estratégica, la presencia de otras etnias y la productividad del valle hacen presumir también que este sitio y los sitios vecinos Wari en el valle, ubicados de manera similar, tuvieron también un carácter militar defensivo. Entonces queda aún por investigar cómo es que los Wari tuvieron presencia administrativa en el valle del río Osmore en Moquegua y no lo tuvieron en los valles de la cuenca del río Chili, que en términos de potencial económico expresado por su extensión agrícola y de disponibilidad de agua es varias veces mayor.

\section{Las conexiones Tiawanaku}

En el presente trabajo solo se analiza las conexiones que se presume tuvieron los Tiwanaku desde la orilla occidental del lago Titicaca hacia los valles del Cuzco y las que estableció con los valles costeros. La conexión más importante es la que unió los santuarios Tiawanaku con los valles del Cuzco, uniendo lugares como Juli-Pomata,
Chucuito, Puno (Hatun Colla), Paucarcolla, Sillustani, y luego Pukara ${ }^{11}$ para alcanzar el abra que actualmente se llama La Raya. Este punto del divortium aqurium de las grandes cuencas de la Amazonía y del lago Titicaca ha sido un lugar sagrado con sus dos montañas: el Huillcanota (Vilcanota) y el Huaripata (Paz Soldán 2014: PLXXXII y Guamán Poma 1987: f270). También se le considera parte de la escenografía grabada en keros ceremoniales coloniales que rememoran el encuentro de los Inca del Cuzco y del Collao (Ramos Gómez 2008: 158-164). Desde el abra, esta conexión siguió por la cuenca del río Vilcanota o Huillcamayu hasta los lugares Wari de Pikillacta y Huaro, y quizá los valles del Cuzco. ${ }^{12}$ Esta ruta económica une cuencas que tienen abundantes recursos y un claro contraste ambiental. En las punas del Titicaca los pueblos Pukara, Tiwanaku y después los Colla lograron dominar la ferocidad ambiental de altura y frío. La abundancia en ganado de camélidos les proporcionó una gran capacidad de producir charqui y tejidos (Murra 2002a). Asimismo lograron neutralizar las bajas temperaturas en terrazas y camellones produciendo tubérculos que luego convertían en chuño. En cambio, los valles del Cuzco eran más propicios para productos de clima templado como el maíz y otras variedades de tubérculos. Esta evidente complementariedad ecológica creó condiciones para intercambios económicos y culturales además de las relaciones religiosas y políticas en ambas direcciones (Glowacki 2014, 201). Se trata de una zona en la que se produce un acercamiento y posiblemente intercambios culturales y económicos entre espacios vecinos y cercanos de Wari y Tiwanaku.

Desde la orilla occidental del lago Titicaca hubo varias conexiones que los Tiwanaku, y las etnias Colla después, establecieron hacia las cuencas del Océano Pacífico. Ellas tuvieron una notoria presencia cultural e ideológica de Tiwanaku, intercambios económicos originados en la diversidad de ambientes ecológicos y recursos económicos y también posibles transferencias tecnológicas en la construcción de terrazas y andenes. Asimismo, se ha constatado la existencia de un mecanismo de compartir recursos de los valles con otras etnias.

Una posible ruta Tiwanaku se dirigió hacia las cuencas del río Colca-Camaná y del Chili-Vítor, a lo que en el Intermedio Tardío fue el espacio de los Collagua, que luego sería el Cuntisuyo de los Inca. Es una ruta que llega al Colca por Sumbay y se conecta con el Cuzco. Una segunda ruta, 
posiblemente desde el lado noroeste de la cuenca del lago Titicaca, bajó por un lado de la laguna actualmente llamada Salinas y descendió por el lado sur del nevado Pichu-Pichu hacia los valles de los ríos Sabandía y Yarabamba, tributarios del río Chili. En estos valles se han encontrado varios lugares Tiwanaku como Yumina, Pillo, Kasapatac y Sonqonate, cuyos estudios revelan una activa presencia cultural y religiosa aunque quizá no administrativa (Cardona 2010). Pero también muestran la posibilidad de una coexistencia con etnias locales y con presencia Wari que recién se está estudiando, por ejemplo en Corralones, a la salida del valle y otros sitios Wari más hacia abajo en los valles de los río Siguas y Camaná (Jennings y Yépez Álvarez 2012, Jennings 2014, Owen 2010 y Neira 1990).

Más hacia el sur existe otra posible conexión desde Hatuncolla que se dirigió al abra de San Antonio de Esquilache y bajó por los ríos Ichuña y Tambo hasta Carumas, de donde posiblemente se conectó con el río Osmore, donde están los sitios arqueológicos Tiwanaku de Omo y Chen Chen (Owen y Goldstein 2001). En este valle no muy grande pero fértil también se ha constatado la presencia Wari en cerro Baúl, Mejía y Trapiche. Además hubo una cultura local llamada Huarancane ${ }^{13}$, lo que ha generado una discusión acerca de la interacción entre estos grupos étnicos (Green y Goldstein 2010). También hubo rutas Tiwanaku hacia los valles costeros de Sama, Tacna, y Lluta y Azapa. En Azapa se encontró cerámica similar a la Tiwanaku encontrada en Omo, en el valle de Moquegua en 1986 (Goldstein 2001: 155-167). Estas evidencias sugieren el uso de la producción costera de maíz y la elaboración generalizada de chicha tanto como alimento como para fines rituales ${ }^{14}$.

Además de las evidencias señaladas han surgido en la reciente década estudios lingüísticos sobre el quechua, aymara y puquina que señalan la presencia de puquina hablantes cuyo origen está en los alrededores del lago Titicaca y que podrían corresponder al habla de los tiwanaquenses o de un pueblo de ese espacio (Bouysse-Casaggne 2010, Cerrón Palomino 2012 y Domínguez 2014). Esto ha permitido identificar topónimos en idioma puquina que se ubican en cuencas de Arequipa (Socabaya, Mollebaya, Tiabaya, Polobaya), Moquegua (Coalaque, Coralaque, Puquina, Carumbaya, Carumas) y en Tacna (Ilabaya, Curibaya), así como también la denominación de los volcanes Misti (Putina) y Huaynaputina (Julien 2010). Estos antecedentes confirman conexiones culturales de pueblos circunlacustres hacia cuencas costeras cuyo origen es anterior a españoles y a los Inca.

Hay una conexión Tiwanaku que ha sido propuesta por el arqueólogo Julián Santillana de un corredor sagrado entre santuarios de Pachacámac y los de Tiwanaku y que incorpora lugares sagrados como Pukara, Cuzco, Huaytará y otros (Santillana 2012: 77-81). Su análisis surge del estudio para explicar la construcción del complejo de Vilcashuamán. Santillana sugiere que en esta región los recursos económicos no son significativos y que la razón de construir este "cuzco" fue para consolidar la sacralidad de ese espacio ubicado en este corredor sagrado ${ }^{15}$. Si existió un corredor sagrado entre Tiwanaku y Pachacámac, basado principalmente en consideraciones ideológicas y culturales, se reforzaría la idea que cuando estas sociedades declinaron las conexiones religiosas y quizá las económicas permanecieron. El prestigio de ciertos santuarios, huacas y oráculos se mantuvo o reforzó con los cambios políticos. Wari e Inca llegaron en diferentes momentos a Pachacámac, Pariacaca, Sarasara o Coropuna. Igualmente los Inca veneraron y reforzaron el culto en los santuarios meridionales del lago Titicaca (Ramos Gavilan 1976, 36-44). Cuando las entidades políticas Wari y Tiwanaku dejaron de existir, es posible que algunas conexiones continuaran. De esa forma se puede conceptuar que la construcción de un estado Inca en los valles del Cuzco se hizo sobre la existencia de redes conectivas religiosas y de intercambios económicas que ya existían.

\section{Comentarios finales}

Lo primero que sugiere el examen holístico de las redes de conexión entre las sociedades Wari, Tiawanaku e Inca es que las dinámicas de expansión y de formación social en los Andes meridionales se dio desde Nazca y Wari, por un lado, y desde Tiwanaku por el otro. Esto confirma la necesidad de mirar con mucho sentido crítico las fuentes documentales de la colonia temprana que tiene un claro sesgo Cuzco centrista.

Un segundo aspecto que consideramos relevante destacar es que se ha identificado al menos tres áreas de tensión o encuentro entre los Wari y los Tiwanaku: la zona alrededor del nudo de Vilcanota, entre Sicuani y Ayaviri, la cuenca del Chili-Vitor en Arequipa y el río Osmore en Moquegua. En estas 
áreas ambas sociedades resolvieron su enfrentamiento con diferentes estrategias y de una manera dialéctica, con arreglos de sus ideologías y ritos religiosos, compartiendo los recursos económicos de cuencas en que se encontraron y mediante intercambios culturales y económicos.

Algunas conexiones, como las religiosas y económicas, posiblemente fueron más estables y ello permitió que los reinos regionales que surgieron en el llamado Intermedio Tardío tuvieran procesos de rearticulación del que surge el estado Inca. Los santuarios y huacas de mayor prestigio siguieron manteniendo su actividad y también los principales intercambios económicos. El mullu, el algodón, los tejidos, la coca, el ají y muchos otros productos siguieron circulando. Lo que declinó y se modificó en ese proceso histórico fueron principalmente las elites y sus estructuras de poder político con sus expresiones más relevantes de prestigio y acumulación socioeconómica. Sobre esta declinación de Wari y Tiwanaku si bien se tienen algunas pistas, sobre todo de orden climatológico, aun falta conocer más acerca de sus causas.

Otro aspecto concluyente es que en ese periodo hay evidencia de intensos y frecuentes intercambios económicos. Wari y Tiwanaku, además de una organización política y una religión establecieron una red de conexiones económicas y formas de manejo de los recursos. En su tiempo definieron el alcance del uso de los recursos económicos, en particular la frontera agrícola que serviría para los siguientes siglos. Este es un antecedente importante para lo que los Inca harán después con un estado más complejo.

Por último, destacar que el análisis de las evidencias arqueológicas, su relación con sistemas ambientales y la ubicación de los recursos económicos, deja en claro que todas estas conexiones estuvieron muy articuladas socialmente entre sí. De manera particular es importante destacar la especial articulación entre lo religioso y los movimientos económicos.

\section{Referencias Citadas}

Bouysse-Cassagne, Thérèse

2010 Apuntes para la historia de los puquina hablantes. Boletín de Arqueología PUCP N ${ }^{\circ}$ 14. Lima: 283-307.

Burger, Richard

2006 Interacción Interregional entre los Andes Centrales y los Andes centro sur: el caso de la circulación de la obsidiana. Esferas de Interacción prehistóricas y fronteras nacionales modernas: Los Andes sur centrales. Instituto de Estudios Peruanos: 423-441. Lima.

Cardona, Augusto

2010 Poblaciones Tiwanaku asentadas en el Valle de Arequipa: una frontera física y cultural. Revista Historia 9. Arequipa: 21-35.

Victoria Castro, Varinia Varela, Carlos Aldunate y Edgardo Araneda

2004 Principios orientadores y metodología para el estudio del Qhapaqñan en Atacama: desde el Portezuelo del Inka hasta Río Grande. Chungara, Revista de Antropología Chilena: V. 36: No 2: 463-481.

Cieza de León, Pedro

1988 La Crónica del Perú. Peisa. Lima.

Cerrón-Palomino, Rodolfo

2012 Las lenguas de los Incas: el puquina, el aimara y el quechua. Peter Lang Pub Incorporated. Frankfurt am Main.

Curátola, Marco y Ziòlkowski, Mariusz (Eds).

2008 Adivinación y oráculos en el mundo andino antiguo. Instituto Francés de Estudios Andinos y Fondo Editorial Pontificia Universidad Católica del Perú. Lima.

Curátola, Marco

2008 La función de los oráculos en el Imperio Inca. En Curátola et al. 2008: 15-69.
Conlee, Christina A. y Schereiber, Katharine J.

2006 The role of intermediate elites in the Balkanization and reformation of Post Wari society in Nasca Peru. Intermediate elites in Pre-Columbian states and empires. Christina M. Elson and R. Alan Covey, eds. University of Arizona Press. Tucson.

Dillehay, Tom D. y Patricia J. Netherly (Eds.).

1998 La Frontera del Estado Inca. Fundación Alexander von Humbold y Editorial Abya-Yala. Quito.

Domínguez, Nicanor

2014 The puquina language in the early colonial Southern Andes (1548-1610): A geographical analisis. Journal of Latin American Geography: 13(2).

Espinoza Soriano, Waldemar

1964 Visita hecha a la Provincia de Chucuito por Garci Diez de San Miguel en el Año 1567. Ed. Casa de la Cultura del Perú. Lima

Fonseca Santa Cruz, Javier

2011 El rostro oculto de Espíritu Pampa, Vilcabamba, Cusco. CONCHOPATA, Revista de Arqueología $N^{o}$ 3: 229-234. Huamanga.

Frame, Mary

1999 Textiles Chuquibamba, 1000-1475 d.C. Museo de Arte de Lima. Lima.

Garaycochea, Carlos F.

2013 La ruta de la chonta en las conexiones económicas prehispánicas. Congreso de Historia Económica: Agosto de 2013 (Ponencia). Huamanga.

2014 "Los límites del modelo económico de Murra". Allpanchis 76: 173-232.

Garcilaso de la Vega Inca

1959 Comentarios Reales de los Incas. Lima. Librería Internacional del Perú. (1609). 
Green, Ulrike Matties y Goldstein, Paul S.

2010 The Nature of Wari presence in the Mid-Moquegua Valle: Investigating contact at Cerro Trapiche. En Jennings 2010: 19-36.

Glowacki, Mary y McEwan, Gordon

2001 Pikillacta, Huaro y la gran región del Cuzco: Nuevas Interpretaciones de la ocupación Wari de la sierra sur". Boletín de Arqueología PUCP N ${ }^{o}$ 5: 31-49. Lima.

Glowacki, Mary

2014 Imperialismo en el Horizonte Medio: Una reevaluación del paradigma clásico, Cuzco, Peru". Boletín de Arqueología PUCP N ${ }^{o}$ 16: 189-207. Lima.

Goldstein, Paul S.

2003 From stew eaters to maize drinkers: The chicha economy and the Tiawanaku expansion. The archeology and politics offood and feasting in early states and empires. Tamara $\mathrm{L}$. Bray, Ed. Kluwer Academy/Plenum Publishers. 143-172. New York.

Huertas, Lorenzo

2009 Injurias del tiempo. Desastres naturales en la historia del Perú. Universidad Ricardo Palma. Editorial Universitaria. Lima.

Hyslop, John

2014 Qhapaq Ñan: El sistema vial inkaiko. Ediciones COPEPetroperú. Lima.

Isbell, William $\mathrm{H}$.

2010 La arqueología Wari y la dispersión del quechua. Boletín de Arqueología PUCP No 14: 199-220. Lima.

Jennings, Justin. Ed.

2010 Beyond Wari Walls . Regional perspectives on Middle Horizon Peru. University of New Mexico Press.

Jennings, Justin

2010a Beyond Wari Walls. En Jennings 2010: 1-33.

Jennings, Justin

2010b Becoming Wari: Globalización and the role of the Wari State in the Cotahuasi Valley of Southern Perú. En Jennings 2010: 37-56.

Jennings, Justin

2014 Revaluando el Horizonte Medio en Arequipa. Boletín de Arqueología PUCP N $N^{o}$ 16. 165-187. Lima.

Jennings, Justin y. Yépez Álvarez,Willy J. Eds.

2012 ¿Wari en Arequipa? Análisis de los contextos funerarios de La Real. Museo Arqueológico José María Morante, Universidad Nacional de San Agustín de Arequipa. Ed. electrónica.

Julien; Catherine

2011 Las huacas pacariscas de Arequipa y el volcán Misti. HISTORIA $N^{o}$ 10. Universidad Nacional San Agustin. 105132. Arequipa

Lechtman, Heather (Ed.)

2006 Esferas de Interacción prehistóricas y fronteras nacionales modernas: Los Andes sur centrales. Instituto de Estudios Peruanos. Lima.

Lechtman, Heather y Andrew MacFarlane

2006 Bronce y redes de intercambio andino durante el Horizonte Medio: Tiwanaku y San Pedro de Atacama. En Lechtman 2006: 503-539.

Masuda, Shozo, Izumi Shimada and Craig Morris (Eds.) 1985 Andean Ecology and Civilization: An Interdisciplinary Perspective on Andean Ecological Complementarity. University of Tokyo Press.
Murra, John

2002 El mundo andino. Población, medio ambiente y economía. Instituto de Estudios Peruanos. Lima.

Murra, John

2002a "Un reino aymara" (1968). En Murra 2002, 183-206.

Neira Avendaño, Máximo

1990 Arequipa prehispánica. Estilo Churajón. Historia General de Arequipa. Editorial Bustamante de la Fuente: 129-154. Arequipa.

Ochatoma Paravicino, José y Cabrera Romero, Martha

2000 Ideología religiosa y organización militar en la iconografía del área ceremonial de Conchopata. Wari: arte precolombino peruano . Luis Millones Ed. Fundación El Monte: Museo Nacional de Arqueología, Antropología e Historia del Perú. 173-212. Sevilla, Lima.

Orefici, Giuseppe

1998 Max Uhle y las investigaciones arqueológicas en la región de Nasca. Revista Indiana 15. Instituto Iberoamericano Berlín.

Owen Bruce D. y Goldstein Paul S.

2001 Tiawanaku en Moquegua: Interacciones regionales y colapso. Boletín de Arqueología PUCP, No 5: 169-188. Lima

Owen, Bruce D.

2010 Wari in the Camaná Valley: A different kind of horizon. En Jennings 2010: 57-77.

Paz Soldán, Mariano Felipe

2014 Atlas geográfico del Perú. Re-edición Instituto Francés de Estudios Andinos-Fondo Editorial Pontificia Universidad Católica del Perú. (1865). Lima.

Poma de Ayala, Guamán

1987 Nueva Crónica y Buen Gobierno. Historia 16. Tomos A y C. (1615). Madrid.

Ramos Gavilán, Alonso

1976 Historia del célebre Santuario de Nuestra Señora de Copacabana. Academia Boliviana de Historia. (1621). La Paz.

Ramos Gómez, Luis

2008 La escena del "Brindis con el Sol" en los queros o vasos de madera andinos de época colonial. Revista Española de Antropología Americana. V 38, núm. 1: 139-166. Madrid.

Regalado de Hurtado, Liliana

2013 ¿Visión de los vencidos o subalternidad? Discursos históricos en las crónicas coloniales. Las Crónicas Coloniales. Fuentes para historias comparadas. Ed. Liliana Regalado de Hurtado. Ministerio de Cultura-Fondo Editorial Pontificia Universidad Católica del Perú: 17-44. Lima.

Rosenblitt, Jaime

2013 Centralidad Geográfica, Marginalidad Política: La Región de Tacana-Arica y su comercio, 1778-1841. DIBAM. Santiago.

Rostworowski, María

1992 Pachacámac y el Señor de Los Milagros: Una trayectoria milenaria. Instituto de Estudios Peruanos. Lima.

2004 Costa Peruana Prehispánica. Obras Completas III. Instituto de Estudios Peruanos. Lima.

Santillana, Julian I.

2012 Paisaje sagrado e ideología inca: Vilcas Huaman. Institute of Andean Research y Fondo Editorial Universidad Católica del Perú. Lima.

Schreiber, Katharina J.

1991 The association between roads and polities: evidence for Wari roads in Perú. Charles D. Trombold (Ed). Ancient 
road networks and settlement hierarchies in the New World. Cambridge University Press: 243-252. Cambridge, UK. Schreiber, Katharina J.

2000. Los Wari en su contexto local: Nazca y Sondondo. Boletín de Arqueología PUCP $N^{o}$ 4: 425-447. Lima.

Schreiber, Katharina J.

2011 El problema del Horizonte Medio. CONCHOPATA, Revista de Arqueología $N^{o}$ 3: 259-304. Huamanga.

Schreiber, Katharina J.

2014 "Una aproximación a las investigaciones sobre Wari: Paradigmas y perspectivas sobre el Horizonte Medio". Boletín de Arqueología PUCP No 16: 11-23. Lima.

Schreiber, Katharina J. y Josué Lancho Rojas

2006 Aguas en el Desierto. Los puquios de Nasca. Fondo Editorial Universidad Católica del Perú. Lima.

Shady Solís, Ruth

1988 La época Huari como interacción de las sociedades regionales. Revista Andina $N^{o}$ 11: 67-133. Cuzco.

Stanish, Charles; Frye, Kirk Lawrence; de la Vega, Edmundo y Seddon, Matthew T.

2005 Tiwanaku Expansion into the Western Titicaca Basin. Advances in Titicaca Basin Archaeology I, Eds. C. Stanish, A. Cohen, and M. Aldenderfer. Cotsen Institute of Archaeology Press, Los Angeles.

Stanish, Charles; De la Vega, Edmundo; Moseley, Michael; Williams, Patrick Ryan; Chávez, Cecilia; Vining, Benjamin y

Le Favre, Karl

2010 Tiwanaku trade patterns in Southern Peru. Journal of Anthropological Archeology: 29: 524-532.

Tarragó, Myriam Noemi

2006 Espacios surandinos y la circulación de bienes en época Tiwanaku. Esferas de Interacción prehistóricas y fronteras nacionales modernas: Los Andes sur centrales. Instituto de Estudios Peruanos: 331-369. Lima.

Taylor, Gerald

1987 Ritos y Tradiciones de Huarochirí. Manuscrito de comienzos del siglo XVII. Instituto de Estudios PeruanosInstituto Francés de Estudios Andinos. Lima.
Thompson, L.G., Mosley-Thompson E., Dansgaard W. y P. M. Grootes

1986 The Little Ice Age as Recorded in the Stratigraphy of the Tropical Quelccaya Ice Cap. Science 17 October 1986: 361-364.

Tung, Tiffiny A.

2012 Violence, Ritual, and the Wari Empire: A Social Bioarchaeology of Imperialism in the Ancient Andes. University Press of Florida.

Williams, Patrick R., Isla, Johny A. y Nash, Donna J.

2001 Cerro Baúl: Un enclave Wari en interacción con Tiwanaku". Boletín de Arqueología PUCP, $N^{o}$ 5: 69-87. Lima.

Ziòlkowski, Mariusz

2008. Coropuna y Solimana: los oráculos de Condesuyos. En: Curátola y Ziòlkowski, 2010: 121-159.

Zuidema, R. Tom

2011 Chuquibamba Textiles and Their Interacting Systems of Notation: The Case of Multiple Exact Calendars". Their way of writing. Scripts, Signs, and Pictographies in PreColumbian America. Eds. Elizabeth H. Boone and Gary Urton. DORLC. Washington: 251-276.

\section{Fuentes Cartográficas}

Mapas departamentales de Lima, Junín, Huancavelica, Ica, Ayacucho, Arequipa, Cuzco, Moquegua, Puno y Tacna. Instituto Geográfico Nacional. Carta Nacional 1: 100,000.

Mapa Ecológico del Perú. ONERN. 1976

http: //mapasplanosperu.blogspot.com/2011/02/mapa-ecologicodel-peru-onern-1976.html

http: //eusoils.jrc.ec.europa.eu/esdb_archive/EuDASM/latinamerica/images/maps/download/pe12006_8bi.jpg

Mapa Ecológico del Perú. 1995

Guía Explicativa del Mapa Ecológico del Perú. Lima 1994.

http: //es.slideshare.net/bryanerj/gua-explicativa-delmapa-ecolgico-del-per-1995

Proyecto Qhapac Ñan. 2003-2004. Mapas Electrónicos de componentes arqueológicos. Macrorregión Centro y Sur.

\section{Notas}

1 Esta ponencia es un avance de una investigación mayor sobre la economía prehispánica en los Andes.

2 Existen varias hipótesis acerca de la organización económica de los Inca como el enfoque socialista de Louis Baudin, los modos de producción marxista de Waldemar Espinoza, Emilio Choy y Jurgen Golte, y el modelo de la verticalidad de John Murra, en tensión crítica con conceptos planteadoss por Kosok, Wittfogel y Rostworowski sobre las civilizaciones costeras. Desde 1985 se planteó el modelo de la "complementariedad ecológica" (Masuda et al. 1985).

3 Se ha consultado algunos mapas e informes del Proyecto de Qhapaq Nan del Ministerio de Cultura y también el estudio completo de John Hyslop (Hyslop 2014).

4 Los 16 principales volcanes son: Quinsachata, Sara Sara, Coropuna, Solimana, Hualca Hualca, Sabancaya, Ampato, Huambo, Chachani, Misti (Putina), Pichu Pichu, Huaynaputina, Ubinas, Ticsani, Tutupaca y Yucamani. En el norte de Chile: Tacora, Parinacota y Tarapacá.
5 Los sistemas ambientales son resultado de la interacción de factores como vientos, temperaturas, altura, distancia ecuatorial, calidad y morfología de suelos, humedad y muchos otros. Este enfoque se basa en desarrollos teóricos de especialistas como Karl Troll, quien propuso la idea "ecología paisaje", o el concepto de "geosistemas" de Olivier Dollfuss y, finalmente, las "zonas de vida" de Leslie Holdridge, que es el esquema que se usa en el Perú desde 1976 para definir el Mapa Ecológico con 84 zonas ecológicas. La antigua propuesta de 8 regiones naturales de Pulgar Vidal (1939) y el concepto de pisos ecológicos, basado solo en la altitud sobre el nivel del mar, han quedado superados por el de zonas de vida o ecológicas.

6 Se usa la convención que designa a Huari como la ciudad en Ayacucho y Wari su civilización. De similar manera se refiere a "los Inca" como civilización Inca.

7 Los valles de Nazca, Ica y Pisco nacen en la cordillera y puna de Ayacucho y Huancavelica. Hay dos abras histórica y geográficamente más convenientes: Huaytará y la zona 
de Puquio desde de Pampa Galeras. Ya en tiempos Inca Huaytará e Incawasi, a $25 \mathrm{~km}$ de distancia, se convierten en lugares estratégicos para controlar estos valles costeros.

8 Este espacio fue la base de operaciones de los Inca de Vilcabamba.

9 Esto no excluye la posibilidad de una ruta Wari desde Pikillacta o Huaro hacia la Amazonía.

10 Descubierto recientemente por un equipo peruano polaco de arqueólogos bajo la dirección de Milosz Giersz.

11 También se puede considerar la zona de Huancané Putina, como parte del espacio central Tiwanaku alrededor del lago Titicaca (Stanish et al. 2005).

12 Un desarrollo analítico más amplio implica incorporar la mitología creacional del Cuzco.

13 Palabra de la lengua puquina.

14 En la Colonia hasta la república temprana muchas de estas rutas de Moquegua,Tacna y Arica se integraron al sistema comercial con el altiplano (Espinoza 1964; Rosenblitt
2013). Queda por ampliar este análisis con las conexiones tiwanaquenses hacia Atacama (Castro 2004) y hacia otros espacios (Tarragó 2006).

15 Una hipótesis alternativa es que sí hubo una razón económica compatible al argumento del corredor religioso y de la pobreza de recursos de la zona de Vilcashuamán. Los Inca conocieron y quizá tuvieron relaciones culturales y económicas con los valles costeros en sus peregrinaciones a Pachácamac, apreciando el potencial de sus recursos especialmente agrarios. Pero antes fue necesario consolidar su dominio en Ayacucho que tenía etnias con una marcada tradición guerrera, como los Chankas. Ese período de consolidación, quizá de varias décadas, se refleja en la construcción de un "cuzco" como el de Vilcashuamán y los sitios defensivos de Huaytará e Incawasi. Después de la consolidación en Ayacucho, los Inca pudieron conquistar los extensos y ricos valles de Nazca, Ica, Pisco, Chincha y de Pachacámac. 
